\title{
Abiotic factors affecting habitat selection by two invasive gammarids Dikerogammarus villosus and Pontogammarus robustoides
}

\author{
Jarosław Kobak (D) Lukasz Jermacz • Joanna Marcińczyk • Ewa Bartoszyńska • \\ Daria Rutkowska $\cdot$ Karolina Pawłowska
}

Received: 30 August 2016/Revised: 29 March 2017/Accepted: 6 April 2017/Published online: 18 April 2017

(C) The Author(s) 2017. This article is an open access publication

\begin{abstract}
Identification of habitat preferences of invasive organisms is crucial for predicting their distribution and impact. We conducted laboratory experiments to determine preferences of Dikerogammarus villosus and Pontogammarus robustoides, invasive in Europe, with regard to ionic content (450 and $830 \mu \mathrm{S} / \mathrm{cm}$ in a Y-maze), flow $(0-30 \mathrm{~cm} / \mathrm{s}$ in a flow-through tank with stagnant water refuges) and temperature (a gradient $5-35^{\circ} \mathrm{C}$ ). D. villosus selected the lower salinity, whereas $P$. robustoides did not discriminate between salinities, suggesting that, the raised ionic content in large European rivers cannot explain their absence in small tributaries, as previously postulated. Gammarids never preferred flowing over stagnant water, but could stay in a flow $\leq 10 \mathrm{~cm} / \mathrm{s}$ without behavioural changes. They avoided flow $\geq 15 \mathrm{~cm} / \mathrm{s}$. Gammarids selected warmer water than their acclimation temperatures. Temperature selection by $D$. villosus was related to its acclimation
\end{abstract}

Handling editor: Andrew Dzialowski

Electronic supplementary material The online version of this article (doi:10.1007/s10750-017-3185-4) contains supplementary material, which is available to authorized users.

J. Kobak $(\bowtie) \cdot$ Ł. Jermacz · J. Marcińczyk .

E. Bartoszyńska · D. Rutkowska · K. Pawłowska Department of Invertebrate Zoology, Faculty of Biology and Environmental Protection, Nicolaus Copernicus University, Lwowska 1, 87-100 Toruń, Poland e-mail: jkob73@umk.pl temperature. The choice of $P$. robustoides depended on the season: it preferred a lower temperature in summer than in autumn. Therefore, its thermal preferences were more stable throughout the year, which might be advantageous in shallow, thermally variable areas. Gammarids used environmental variables to select warm, lentic, freshwater locations, which may help them locate an optimum microhabitat and thrive in temporally and spatially variable environments.

Keywords Temperature - Salinity · Water flow · Habitat preference · Ponto-Caspian Amphipoda . Crustacea

\section{Introduction}

Geographic distribution of species at various spatial scales may be driven by multiple factors, including historical (speciation, range shifts) and ecological (habitat selection, competition) processes (Warren et al., 2014). The occurrence of alien species during their early invasion stages may be accidental, depending on a fortuitous place of introduction rather than on their environmental demands (Simberloff \& Gibbons, 2004). Moreover, as many factors act differently in novel areas (e.g. due to the enemy release effect, Torchin et al., 2003), alien organisms may thrive in different ranges of environmental conditions than in their native regions, which is difficult to predict on the 
basis of their ecology in previously occupied locations (Pearman et al., 2008; Medley, 2010). Furthermore, newly established populations may differ in their physiological, behavioural and ecological traits compared to previously established populations (MacMahon, 1996; Llewelyn et al., 2010) due to local adaptations or genetic drift (Bock et al., 2015). Thus, it is difficult to infer ecological processes exclusively from species distribution (Warren et al., 2014) and experimental studies are necessary to determine exact preferences of alien organisms for particular environmental variables and their combinations. Experimental approach would allow researchers to understand the local distribution of alien species, predict areas susceptible to their further expansion and organisms likely to be endangered by their appearance.

Freshwater ecosystems are much more susceptible to biological invasions than most terrestrial and marine environments due to their higher level of variability and isolation, resulting in a greater naïveté of freshwater communities and therefore stronger impacts of invaders (Ricciardi \& MacIsaac, 2011). As abiotic factors in aquatic ecosystems vary across temporal and spatial scales, the ability to detect changes in them and find an optimum microhabitat is crucial for the fitness of motile animals (Lampert \& Sommer, 2007). In freshwater ecosystems, the most important abiotic factors shaping the living conditions include temperature, ionic content of water and flow rate. Other important factors, such as substratum type, oxygen concentration, turbidity, light or $\mathrm{pH}$, depend to a large extent on the above-mentioned conditions (Allan \& Castillo, 2007; Lampert \& Sommer, 2007).

Temperature shapes multiple aspects of animal functioning through its impact on metabolic rate, food availability and oxygen concentration (Hawkins, 1996). Temperature may vary vertically due to the stratification of the water column, as well as horizontally and temporally in shallow waters, affected by shading and solar radiation (Lagerspetz \& Vainio, 2006). For alien species, temperature can be the most important environmental factor determining the possibility of survival, reproduction and establishment in the new area in the case of climatic differences between the donor and recipient regions (Müller \& Baur, 2011). Temperature changes may also induce dispersal of alien species (Rosa et al., 2012).
Hydrodynamics, including water current and wave actions, is a crucial factor in running waters (Allan \& Castillo, 2007), determining substratum quality, turbidity, oxygen content and the possibility of animal movement and settlement, as well as bringing food and infochemicals (Arnold, 1974). Water currents are also an effective way of dispersal of aquatic species (Brittain \& Eikeland, 1988; Allan \& Castillo, 2007), including invasive organisms (Van Riel et al., 2011).

Ionic content is particularly important for stenohaline species, but other organisms may also benefit from the presence of certain ions, e.g. calcium necessary for molluscan shells and crustacean cuticles (Lampert \& Sommer, 2007). Salinity varies horizontally near river outlets to the sea and where affluents enter larger rivers of different ionic contents (Rozengurt, 1971; Grabowski et al., 2009). Raised ionic content may be beneficial for alien species adapted to brackish water and/or unstable salinity conditions (Devin \& Beisel, 2007).

We studied microhabitat selection by two PontoCaspian gammarids Dikerogammarus villosus and Pontogammarus robustoides with regard to water salinity, temperature and current velocity. These two species have been invasive in a large part of Europe since the second half of the twentieth century, inhabiting mainly lower parts of large rivers, dam reservoirs and some lakes (Jażdżewski et al., 2002) and strongly influencing local communities through predation and competition (Dick \& Platvoet, 2000; MacNeil et al., 2011). The physiological responses of these species and critical values of some environmental variables, such as temperature or salinity, have been studied (e.g. Wijnhoven et al., 2003; Dobrzycka-Krahel \& Surowiec, 2011; DobrzyckaKrahel et al., 2015), but data on their active preferences for these factors are limited. Field observations show that both species are euryecious and eurytopic, though D. villosus is often associated with deeper sites and hard substrata (Kley \& Maier, 2005; Boets et al., 2010), whereas P. robustoides inhabits lentic habitats, macrophytes or very shallow sandy areas (Jażdżewski et al., 2002; Żytkowicz et al., 2008). Nevertheless, laboratory experiments have shown that both species prefer similar rocky substrata (Jermacz et al., 2015; Kobak et al., 2015). Thus, some other factors than the substratum itself must be responsible for their separation in the field. 
We intended to (1) determine ranges of environmental variables preferred by both species, to identify conditions under which they are most likely to occur; (2) check for the differences in habitat preferences between the species, explaining their potential co-occurrence or separation in the wild.

We hypothesized that both species would differ in their habitat preferences, which could help explain their field distribution. We expected that gammarids originating from brackish water habitats (Rozengurt, 1971) would exhibit preferences for increased ionic content in water (Piscart et al., 2005), preventing them from entering small, more freshwater affluents of large rivers (Grabowski et al., 2009). We also assumed that both species would select lentic sites (Devin \& Beisel, 2007; Borza et al., 2017), but that $P$. robustoides, as a more common inhabitant of stagnant waters (Jażdżewski et al., 2002) would be relatively less adapted to flow. Finally, we expected that $P$. robustoides would be better adapted to counteract negative aspects of life in very shallow locations (WawrzyniakWydrowska \& Gruszka, 2005; Żytkowicz et al., 2008), such as extreme temperatures.

\section{Materials and methods}

Animals

We collected gammarids from the Włocławek Reservoir (the lower River Vistula, Central Poland, N $52^{\circ} 37^{\prime} 03^{\prime \prime}$, E $19^{\circ} 19^{\prime} 37^{\prime \prime}$ ) using hand nets and artificial substratum traps. In the laboratory, we placed them in 100-1 stock tanks with constantly filtered and oxygenated water and used them in experiments 1-4 weeks after collection. In preliminary tests, we did not observe any changes in gammarid behaviour during this period in laboratory conditions. Gammarids were fed daily with frozen chironomid larvae and commercial fish food. Every week, we exchanged $30 \%$ of the water volume.

We assessed sizes of 100 randomly selected gammarids of each species with ImageJ $1.50 \mathrm{~g}$ software (W.S. Rasband, U.S. National Institutes of Health, Bethesda, Maryland, USA, https://imagej.nih. gov/ij/). Mean body length \pm SD of the studied individuals of $D$. villosus was $15.5 \pm 2.7 \mathrm{~mm}$ and that of P. robustoides: $14.9 \pm 2.3 \mathrm{~mm}$.
General experimental conditions

The experiments were conducted in tap water placed in tanks and aerated for at least $24 \mathrm{~h}$ before the test. Water quality was checked with a multimeter Multi340i (WTW GmbH, Weilheim, Germany). Except the parameters which were manipulated in a given experiment (see below), the conditions in the stock and experimental tanks were as follows: mean ( \pm SD) temperature: $20.5 \pm 1.2^{\circ} \mathrm{C}, \mathrm{pH} 8.0 \pm 0.4$, conductivity $540 \pm 20 \mu \mathrm{S} / \mathrm{cm}$, oxygen concentration $7.8 \pm 1.4 \mathrm{mg} / \mathrm{l}$. The experiments were conducted in homogeneous indirect incandescent light (520 lx) monitored with a light meter (L-20A, Sonopan Ltd., Białystok, Poland). Tank sides were covered with Styrofoam curtains to exclude external stimuli. In all experiments, gammarids were tested in groups of 5-20 individuals (depending on the size of experimental tanks) as we assume this would better correspond to their natural behaviour in the wild, where they are usually exposed to the presence of conspecifics.

\section{Experiment 1: salinity}

Conductivity is a good measure of water salinity (Wagner et al., 2006) and has been used in other studies on amphipod distribution (Grabowski et al., 2009). We used a glass y-maze (Fig. 1) with the source tanks containing water of two different conductivities. We added marine aquarium salt $\left(\right.$ Red Sea Salt ${ }^{\circledR}$ ) to reversed osmosis filtered water to obtain conductivities of 200 and $900 \mu \mathrm{S} / \mathrm{cm}$ in the source tanks, which resulted in the mean $( \pm \mathrm{SD})$ values of $456 \pm 40$ and $831 \pm 34 \mu \mathrm{S} / \mathrm{cm}$ in the $\mathrm{y}$-arms, corresponding to those observed in small tributaries and large rivers in Europe, respectively (Grabowski et al. 2009). The conductivity in the mixing zone was intermediate. The conductivity measured at the sampling site during the collection of gammarids $(653 \mu \mathrm{S} / \mathrm{cm})$ was also intermediate between the y-arms. To control for the effect of acclimation to particular conditions, we tested two groups of gammarids: acclimated in the stock tanks for 3 weeks to the conductivities of 450 and $850 \mu \mathrm{S} /$ $\mathrm{cm}$.

We established the flow (0.5 1/min.) and placed 10 gammarids into the mixing zone of the $y$-maze. Each experimental trial consisted of $5 \mathrm{~min}$. of adaptation 


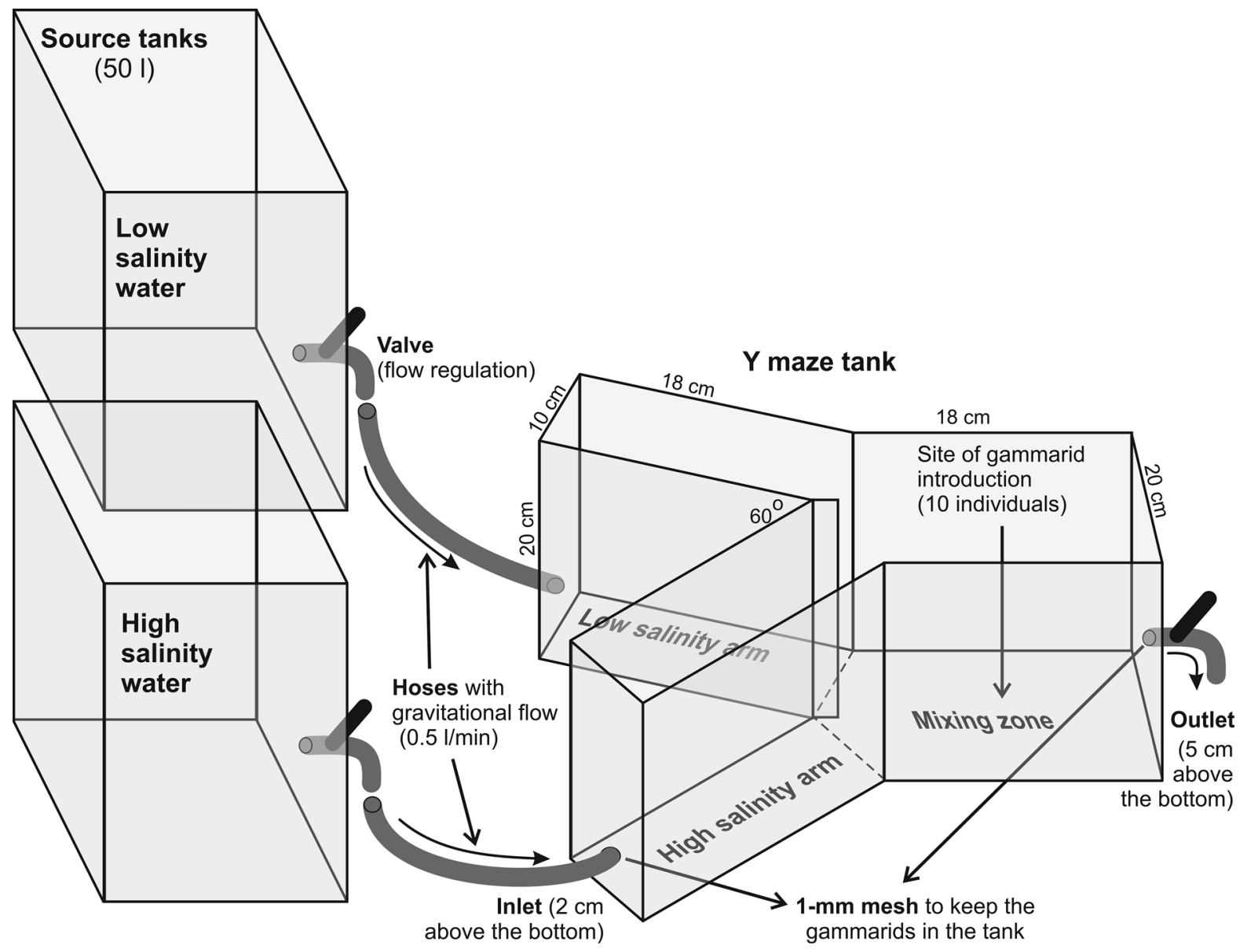

Fig. 1 Y-maze used to test responses of gammarids to salinity (Experiment 1). Dashed lines depict zones of the tank

and $20 \mathrm{~min}$. of the test. Gammarid behaviour was recorded using an IP video camera (SNB-6004, Samsung, South Korea) placed above the tank. The experiment was replicated 15 times. We switched the high and low conductivity $y$-arms and rinsed the tank with tap water between the replicates.

We analysed gammarid behaviour (location in the tank and activity) using Noldus Ethovision $\mathrm{XT}^{\circledR} 10.1$ software. All 10 individuals from a single replicate were treated as a unit and average parameter values for each replicate were used as data points in the further analyses. We determined (1) percentage of time spent by gammarids in each y-maze zone (to check their selectivity) and (2) gammarid activity expressed as a percentage of time spent on moving while present in the zone (as the increased/decreased activity could reflect a continuous search for an optimum location or a freezing response, respectively). We conducted the following analyses:
(1) To check gammarid preferences for particular salinities, we calculated differences $(D)$ between the percentages of time spent in each y-arm (high salinity arm-low salinity arm):

$D=(\mathrm{HS}-\mathrm{LS}) /(\mathrm{HS}+\mathrm{LS})$

where HS and LS are the percentages of time spent in the high and low salinity y-arm, respectively. This formula takes into account the difference relative to the overall time spent in the $y$-arms in a given replicate. Then, we compared the calculated mean difference values in particular treatments with a theoretical value of 0 (indicating no selectivity) using sequential Bonferroni-corrected one-sample t-tests. This approach allowed us to counteract the problem of the lack of independence between the times spent by gammarids in various parts of the arena. 
(2) To check whether gammarids under some conditions reduced their visits to both y-arms, staying in the mixing zone (which would indicate suboptimal conditions in both y-arms), we compared percentages of time spent in the mixing zone using a two-way ANOVA with species and acclimation conditions (low or high conductivity) as factors. This variable could not be directly compared with the y-arms due to their different sizes and shapes.

(3) To compare gammarid activity between the $y$-arms, we used a three-way mixed model ANOVA with species and acclimation conditions as between-subject factors and y-arm conductivity (low or high) as a within-subject factor.

\section{Experiment 2: current velocity}

We used a cross-shaped flow-through tank with flow generated by a water pump (Aquarium Systems NewJet 4500) and regulated by ball valves (Fig. 2). We set up a desired current velocity on the basis of 20 measurements made with an ultrasonic gauge (Greyline Instruments Inc., Massena, NY, USA). We used water velocities of 0 (control), $5,10,15$, and $30 \mathrm{~cm} / \mathrm{s}$, covering the entire range observed in the reservoir (Gierszewski, 2006), from which the animals were collected. The gammarids could enter the main current zone or seek refuge in the stagnant water zones. Within the current zone, they could stay in the flow or adhere to one of the mesh barriers (upstream or downstream). The end walls of the stagnant water zones were also equipped with mesh barriers (Fig. 2) to make them similar in this respect to the current zones.

The tank bottom was devoid of substratum to enable the recognition of animals by the video analysis software. Although this might be regarded as an artificial situation for gammarids, it should be noted that they could utilize mesh barriers, located at the ends of all the zones (Fig. 2), as suitable shelters. Alien gammarids are "sit and wait" animals, which usually stay in the shelters, but sometimes they do migrate, e.g. to find better food areas or mating partners as well as to avoid predators or competitors (Kobak et al., 2016). In such situations, they have to expose themselves to the local flow conditions. Our experimental design can help determine how various current velocities affect the probability of entering the flow area and active relocations of the studied species.

After establishing an appropriate flow, we put 5 gammarids in the main current zone and recorded their behaviour for $30 \mathrm{~min}$. (following a 5-min. adaptation period) with a video camera located above the tank. The experiment was replicated 10-15 times for each treatment.

We analysed gammarid behaviour (location in the tank and activity) using Noldus Ethovision $\mathrm{XT}^{\circledR} 10.1$. Values for all 5 individuals in a single replicate were averaged and these average values were used as data points in the further analyses. Direct comparisons among the tank zones were not possible due the lack of independence among the percentage times spent by gammarids in various parts of the tank and different sizes of the zones. Therefore, we compared gammarid behaviour in the presence of flow with their behaviour in the control, stagnant water conditions in the same tank. We used two-way ANOVAs with species and current velocity as factors to test the following response variables:

(1) The "active" preference of gammarids for flowing water associated with counteracting the water current (time spent actively in the flow), indicated by the percentage of time spent in the main current zone, including the upstream mesh but excluding the downstream mesh.

(2) Passive stay in the flow, when the gammarids did not resist the water current and drifted downstream, indicated by the percentage of time spent on the downstream mesh.

(3) Tendency to seek protection from the excessive flow, shown by the percentage of time spent in the stagnant water zones.

(4) Tendency to occupy the upstream areas, indicated by the distance between the gammarids located in the main current zone and the upstream mesh (with lower values indicating a greater affinity for upstream locations).

(5) Gammarid activity (percentage of time spent on movement in the main current zone relative to the total time spent in this zone, including both mesh barriers), reflecting their ability to withstand the flow (we could expect a decrease in the activity of animals unable to counteract the water current); 


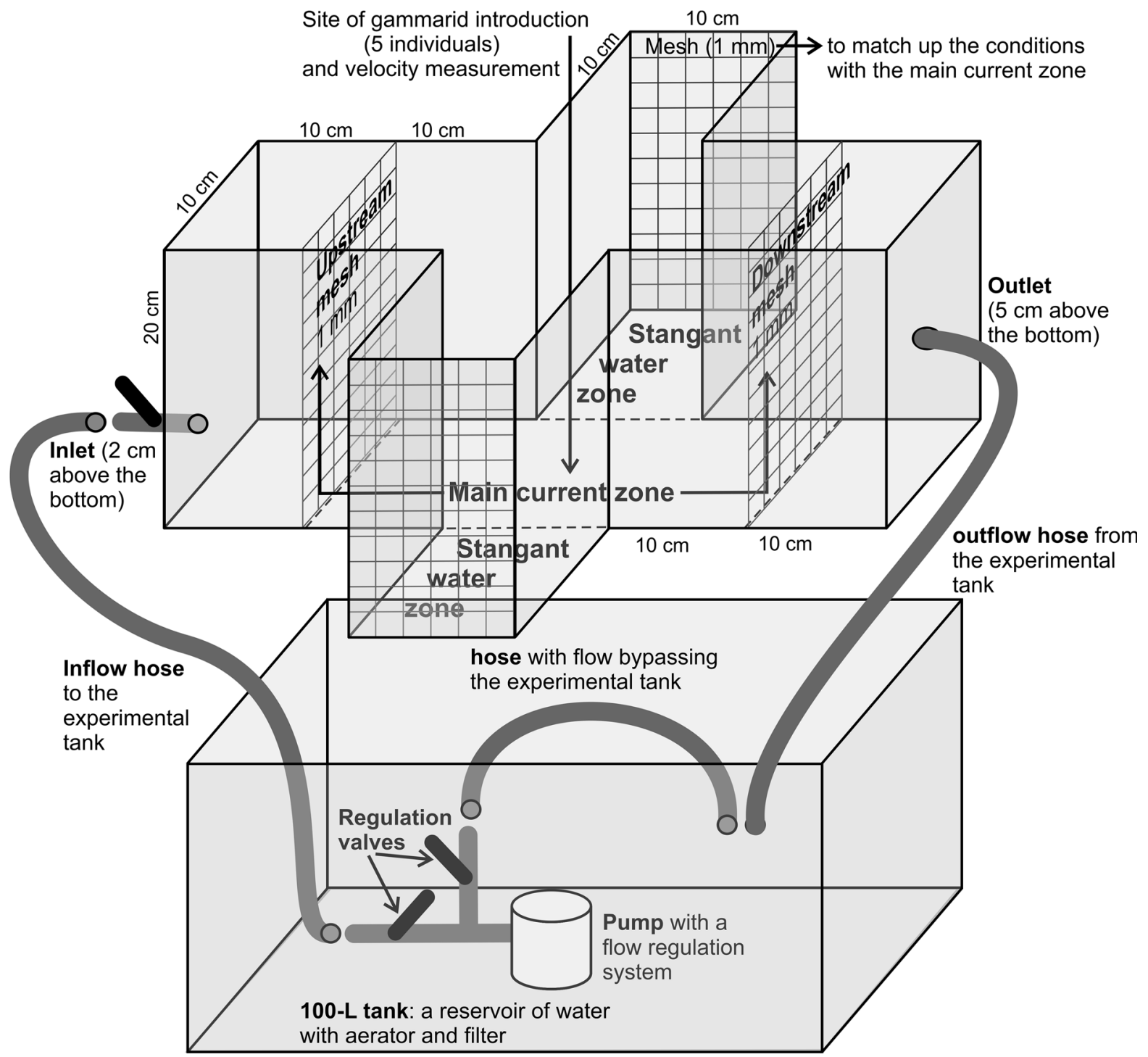

Fig. 2 Flow-through tank used to test gammarid responses to water flow (Experiment 2). Dashed lines depict zones of the tank

(6) Direction choice, shown as the difference between the percentages of time spent on the upstream and downstream movement in the main current zone.

Experiment 3: temperature

We used a thermal gradient $\left(4.7-34.2^{\circ} \mathrm{C}\right)$ with 12 compartments (Fig. 3). Two terminal compartments were separated securely with aluminium (enabling good heat transduction) barriers from the rest of the tank. We equipped one of them with an aquarium cooler Teco R20 (Teco S.1.r., Ravenna, Italy) and the other with a heater, set to 0 and $40^{\circ} \mathrm{C}$, respectively. The remaining, middle part of the tank contained 9 glass barriers raised $1 \mathrm{~cm}$ above the bottom, leaving a common space for free gammarid movement. Such a design allowed temperature differences to be sustained along the gradient. Temperature in each compartment was constantly measured with electronic thermometers to the nearest $0.1^{\circ} \mathrm{C}$. The barriers, their glass guides on the tank walls and thermometer 


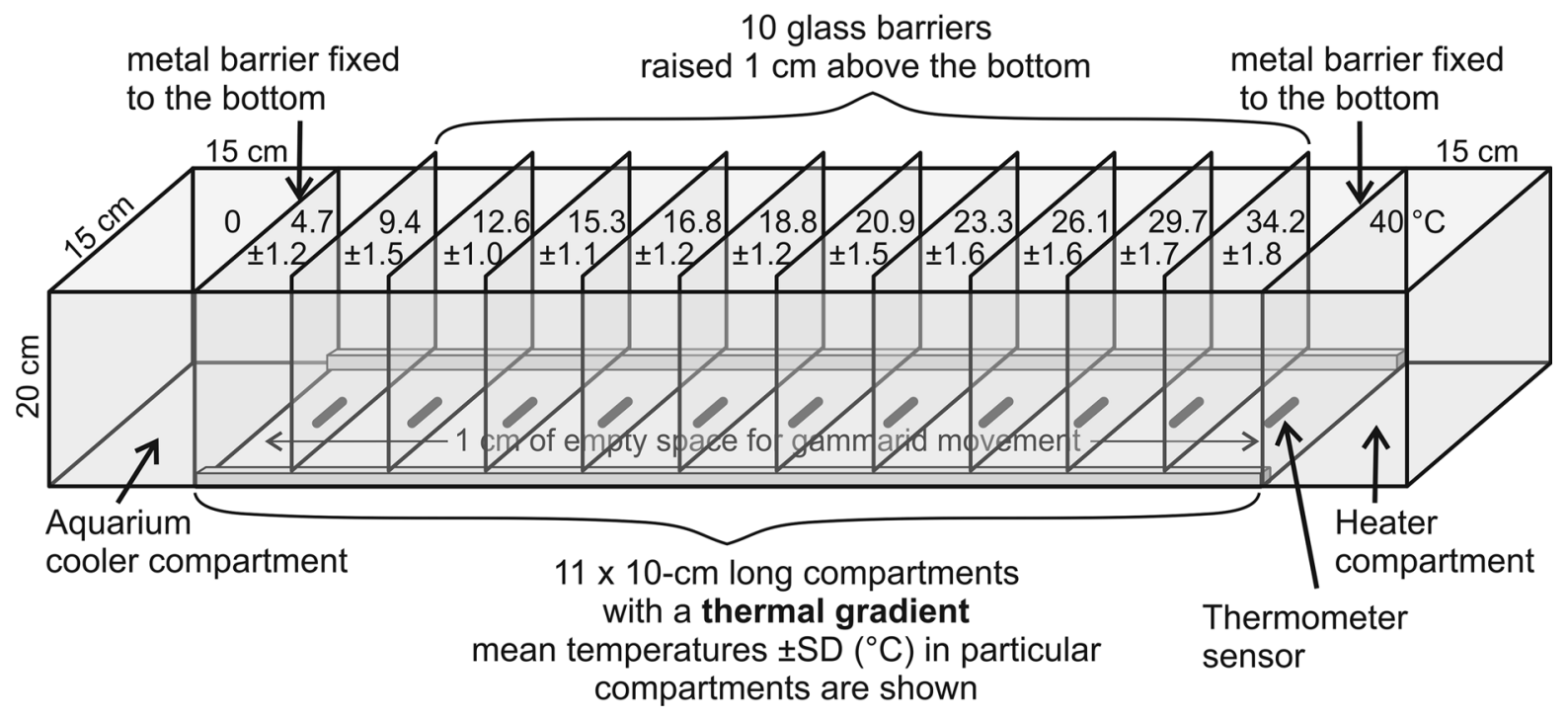

Fig. 3 Thermal gradient used to test gammarid responses to temperature (Experiment 3)

sensors on the bottom served as shelters for gammarids, which allowed the effect of crowding in the corners of the gradient ends to be avoided.

To check the effect of season on gammarid preferences, we collected and tested them in July (water temperature ca. $20^{\circ} \mathrm{C}$ ) and November (ca. $10^{\circ} \mathrm{C}$ ). Moreover, to control for the effect of acclimation conditions, we acclimated gammarids collected in each season for two weeks at 10 or $20^{\circ} \mathrm{C}$. The animals during acclimation were initially placed at the field temperature, which, if needed, was gradually changed at a rate of ca. $1^{\circ} \mathrm{C}$ per h.

We put 20 gammarids into the gradient compartment with the temperature closest to their acclimation conditions to avoid an initial thermal shock. Gammarids are highly mobile and in preliminary trials dispersed evenly in the tank with no thermal gradient after $24 \mathrm{~h}$. After $24 \mathrm{~h}$, we counted gammarids in the compartments. Preliminary trials have shown that such results were comparable with those from a continuous observation, so we gave up the latter, more laborious procedure. The experiment was replicated 10 times. For each replicate, we calculated the mean temperature selected by gammarids (MST):

$\mathrm{MST}=\sum\left(N_{i} * T_{i}\right) / \sum N_{i}$, where $N_{i}$ - the number of animals in compartment $i$; $T_{i}$ - the temperature in compartment $\mathrm{i}$.

We conducted the following analyses:

(1) To check the effect of species, season (summer or autumn) and acclimation conditions (10 or $20^{\circ} \mathrm{C}$ ) on MST, we used a three-way ANOVA;

(2) To check whether gammarids selected temperatures higher or lower than their acclimation temperature, we compared MST values with corresponding acclimation temperatures for each treatment using sequential Bonferronicorrected one-sample $t$-tests.

General statistical remarks

Data were log-transformed prior to analyses to meet the normality and homoscedasticity assumptions (checked with Shapiro-Wilk and Levene tests, respectively) except for the differences between the y-arms (Experiment 1) and movement directions (Experiment 2), which could assume negative values. However, in these two cases, the normality assumption was met without any transformation. The sphericity assumption was confirmed with a Mauchly test for withinsubject factors. Significant ANOVA effects for factors with more than two levels were followed by sequen- 
tial-Bonferroni-corrected t-tests as a post hoc procedure.

\section{Results}

Experiment 1: salinity

Dikerogammarus villosus always selected the low conductivity arm of the y-maze, whereas Pontogammarus robustoides did not discriminate between different conductivities, as indicated by significant one-sample $t$ tests (Fig. 4A; Table S1). Moreover, compared to $P$. robustoides and the low acclimation conductivity treatment, D. villosus acclimated to higher conductivity spent more time in the mixing zone (Fig. 4A, a significant species $\mathrm{X}$ acclimation conductivity interaction in ANOVA: $F_{1,55}=19.3, P<0.001$; see Table $\mathrm{S} 2$ for the full results of statistical tests) and increased its activity (Fig. 4B, a significant species $\mathrm{x}$ acclimation conductivity
Fig. 4 Responses of gammarids acclimated to various conditions to water conductivity (Experiment 1): A Mean $( \pm \mathrm{SE})$ percentage of time spent by gammarids in the $y$-maze arms of different conductivities (the remaining time was spent in the mixing zone); B Mean gammarid activity (percentage of time spent on moving) in the $y$-maze arms of different conductivities. $N$ values show the numbers of replicates. Asterisks denote statistically significant differences in gammarid behaviour between the $y$-arms. Different letters above the bars indicate statistically significant differences between particular treatments with respect to the time spent by gammarids in the mixing zone $(a)$ and gammarid activity in the $y$ arms $(b)$

$$
\text { A } \mathrm{N}=15 \quad 15
$$

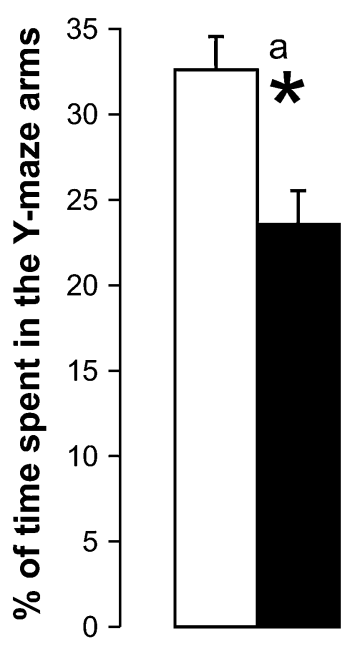

Acclimation to: low salinity

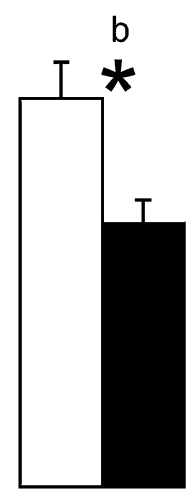

high salinity Dikerogammarus villosus

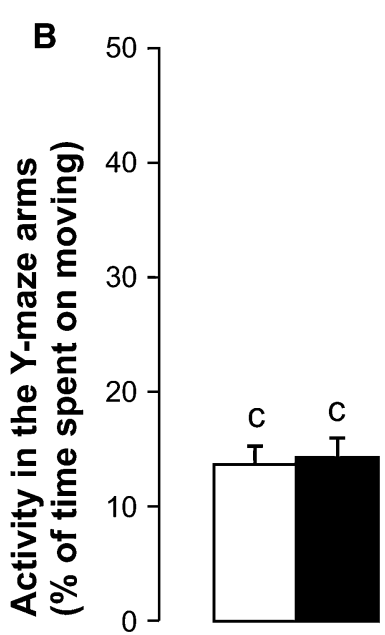

Acclimation to: low salinity

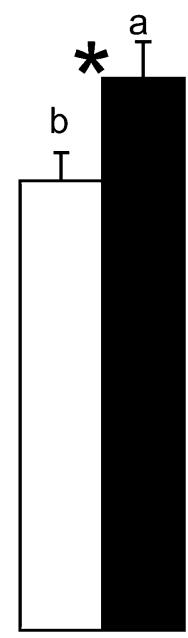

high salinity

Dikerogammarus villosus
15

14

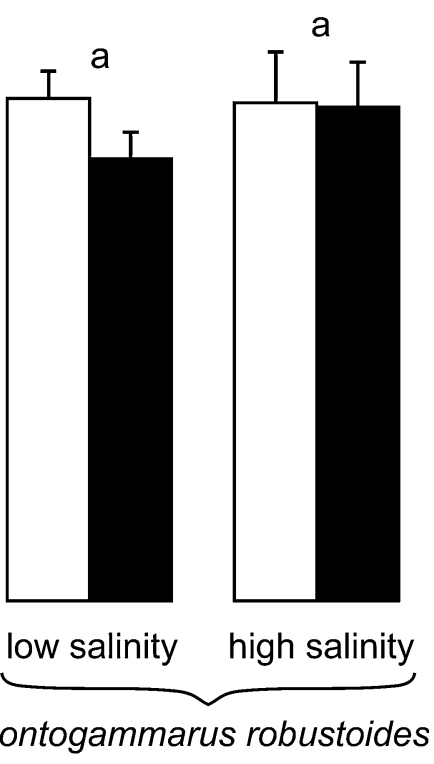

Pontogammarus robustoides
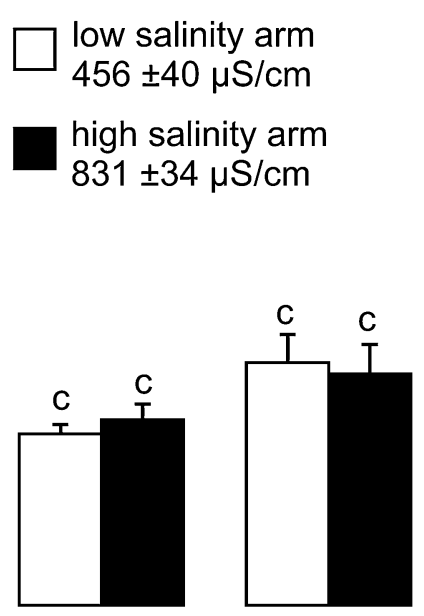

low salinity high salinity Pontogammarus robustoides 
$\mathrm{x}$ y-arm conductivity interaction in ANOVA: $\left.F_{1,55}=4.9, P=0.031\right)$.

Experiment 2: current velocity

The distribution of gammarids in the flow-through tank zones was affected by current velocity (significant main effects in ANOVA: $F_{4}, \quad 113=7.1$, $P<0.001 ; F_{4,113}=10.4, P<0.001 ; F_{4,113}=2.8$, $P=0.027$ for the main current \& upstream mesh, downstream mesh and stagnant water zones, respectively; see Table S3 for the full ANOVA results), but not by species. Gammarids never spent more time in flowing water (i.e. in the main current zone or on the upstream mesh) than in the corresponding area under no flow conditions (Fig. 5A). Time spent in flowing water was reduced at the velocities of $15-30 \mathrm{~cm} / \mathrm{s}$. At $15 \mathrm{~cm} / \mathrm{s}$, gammarids more often clung to the downstream mesh, whereas at $30 \mathrm{~cm} / \mathrm{s}$ they moved to the stagnant water zones (Fig. 5A).

In the faster flow $(15-30 \mathrm{~cm} / \mathrm{s})$, both species were located further downstream than at the lower velocities (Fig. 5B, the main effect of current velocity in ANOVA: $\left.F_{4,113}=5.5, P<0.001\right)$. Moreover, $D$. villosus was found further downstream than $P$. robustoides irrespective of the current velocity (the main effect of species in ANOVA: $F_{1,113}=9.3$, $P=0.003)$.

Dikerogammarus villosus was more active than $P$. robustoides (Fig. 5C) and both species were more active at $30 \mathrm{~cm} / \mathrm{s}$ than in the other treatments, resulting in significant main effects of species and current velocity in ANOVA $\left(F_{1},{ }_{113}=16.2\right.$ and $F_{4,113}=10.7$, respectively, $\left.P<0.001\right)$. Dikerogammarus villosus spent significantly more time on the upstream movement than on moving along the flow direction at $30 \mathrm{~cm} / \mathrm{s}$, whereas $P$. robustoides exhibited no such differences (Fig. 5C), which resulted in a significant species $\mathrm{x}$ current velocity interaction in ANOVA $\left.F_{4,113}=2.6, P=0.041\right)$.

\section{Experiment 3: temperature}

Gammarids selected higher temperatures than those to which they had been acclimated, except $D$. villosus acclimated in autumn to a low temperature and $P$. robustoides acclimated in summer to a high temperature, as shown by one-sample t-tests (Fig. 6; Table S4). It should be noted that considerable numbers of individuals, particularly of D. villosus acclimated to a high temperature, moved and stayed in the warmest compartment (Fig. 7), at a temperature of $34 \pm 1.8^{\circ} \mathrm{C}$ (Fig. 3). In general, D. villosus exhibited a stronger tendency to select extreme temperatures (Fig. 7).

The comparison of temperatures selected by gammarids in different treatments revealed significant two-way interactions between all tested factors in ANOVA $\left(F_{1,72}=14.2, P<0.001\right.$ and $F_{1,72}=9.8$, $P=0.002$ and $F_{1,72}=7.3, P=0.009$, for species $\mathrm{x}$ acclimation temperature, species $\mathrm{x}$ season and acclimation temperature $\mathrm{x}$ season interactions, respectively; see Table S5 for the full statistical details). Individuals acclimated to a high temperature selected warmer areas than those acclimated to a low temperature except $P$. robustoides in summer (Fig. 6). Significant seasonal differences were only shown by $P$. robustoides, which selected warmer water in autumn. Moreover, D. villosus acclimated to a high temperature in summer selected warmer areas than $P$. robustoides and this tendency was reversed in the animals acclimated to a low temperature in autumn.

\section{Discussion}

Experiment 1: salinity

Contrary to our expectations, the tested gammarids selected the low conductivity y-arm (D. villosus) or did not exhibit any selectivity ( $P$. robustoides) (Fig. 4A). Even the individuals of D. villosus adapted to high conductivity more often visited the low conductivity zone, though they significantly reduced time spent in both $y$-arms in favour of the mixing zone and increased their activity (Fig. 4B), suggesting that neither of the $y$-arms was optimal for them. Such behaviour contradicts the hypothesis that lower salinity is the reason for the avoidance of small, low-order streams by the Ponto-Caspian amphipods, which allows the native species to find a refuge in such areas, whereas the aliens thrive in large rivers with anthropogenically increased ionic content (Grabowski et al., 2009).

Ponto-Caspian gammarids are good osmoregulators within a wide salinity range (Bruijs et al., 2001; Dobrzycka-Krahel \& Surowiec, 2011; DobrzyckaKrahel et al., 2015) due to their evolution in the highly 
Fig. 5 Responses of gammarids to current velocity (Experiment 2): A Mean $( \pm$ SE) percentage of time spent by gammarids in various tank zones; B mean distance between the gammarids occurring in the main current zone and the upstream end of the tank; C Mean duration of the upstream and downstream movements of gammarids in the main current zone.

$N$ values show the numbers of replicates. Water velocities differing significantly from one another with regard to gammarid behaviour are labelled with different letters (for the times spent in the tank zones shown in panel A, uppercase, lowercase and Greek letters stand for the main current and upstream mesh combined, downstream mesh and stagnant water zones, respectively)
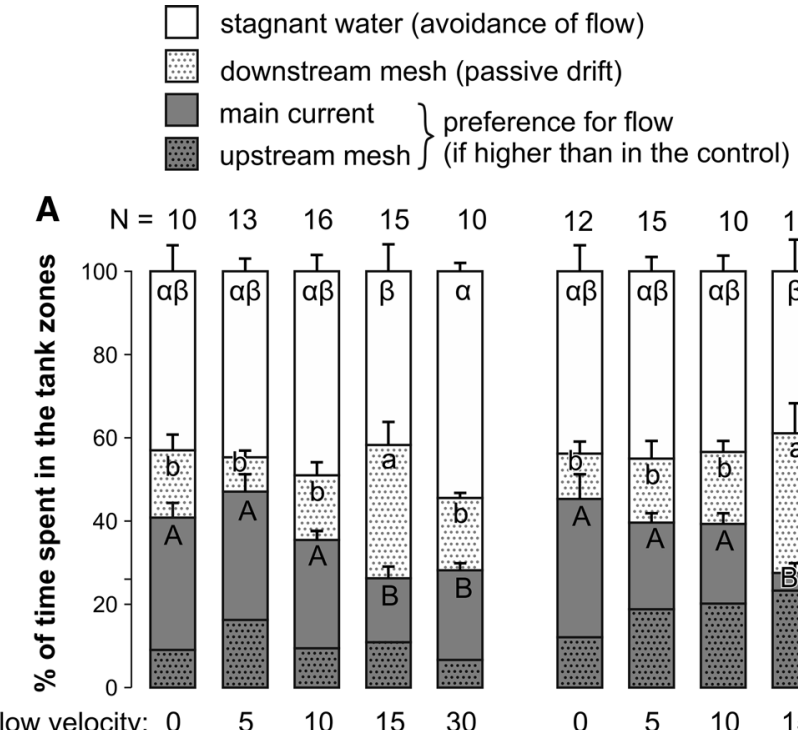

flow velocity: $\begin{array}{lllll}0 & 5 & 10 & 15 & 30\end{array}$ $(\mathrm{cm} / \mathrm{s})$

Dikerogammarus villosus
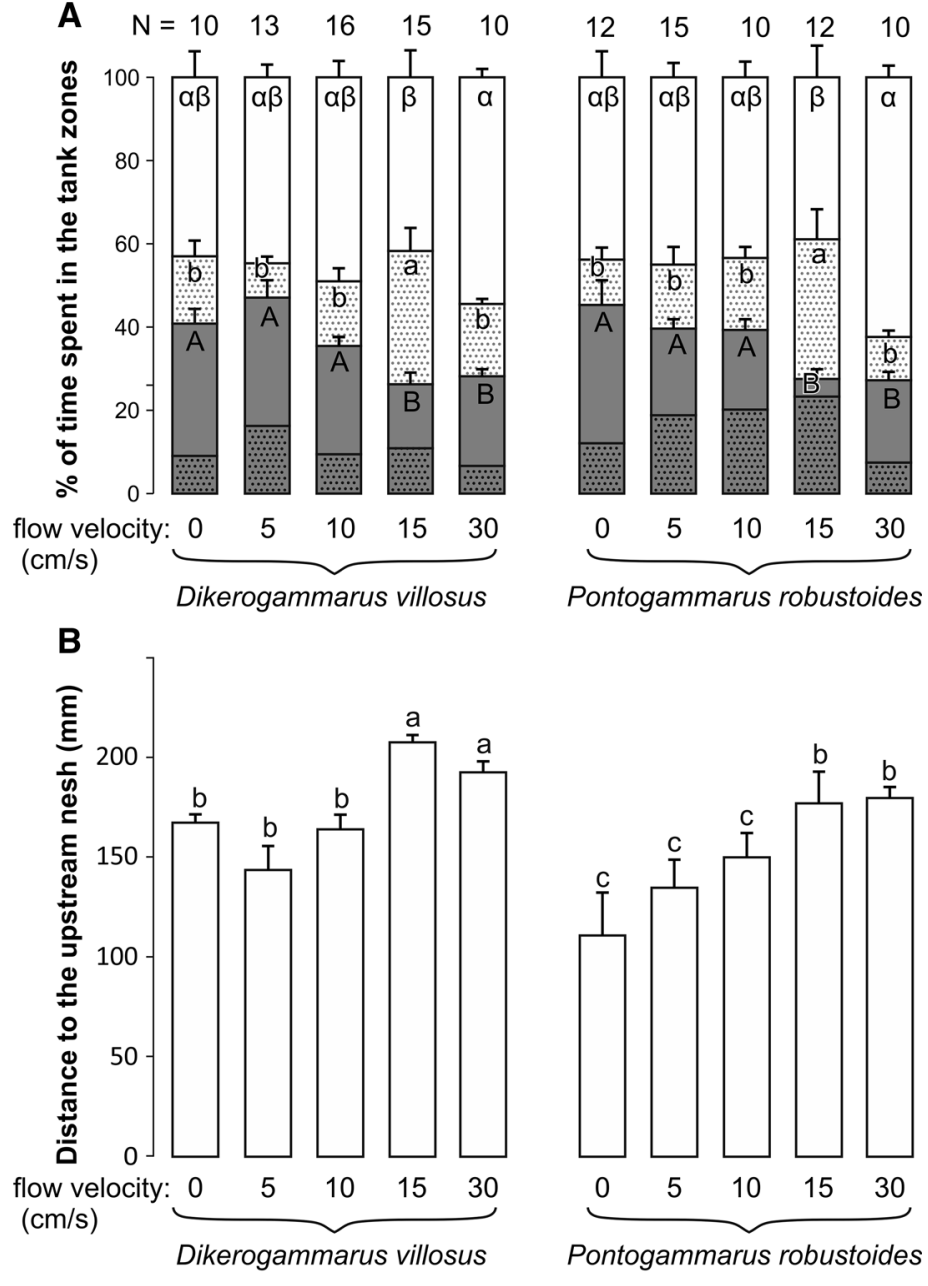

C
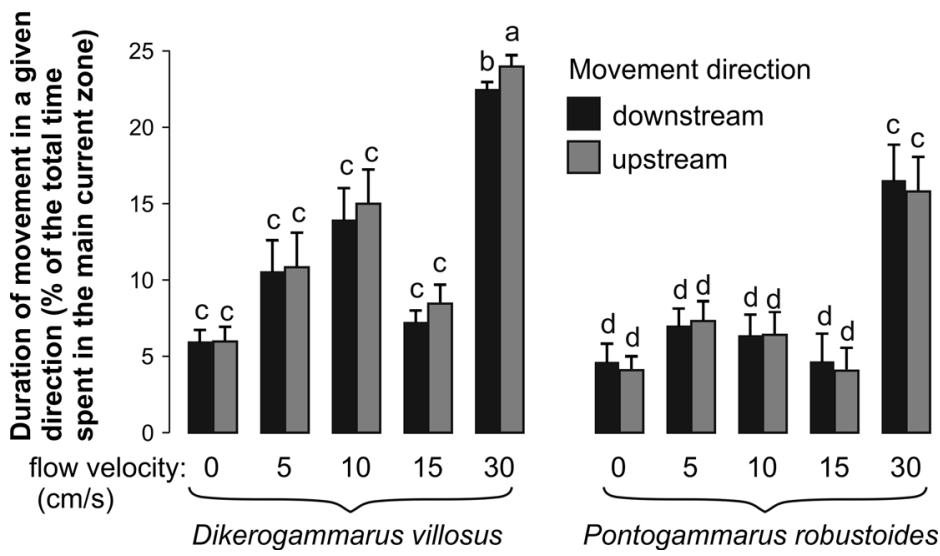
Fig. 6 Mean temperature ( \pm SE) selected by gammarids acclimated to various temperatures in various seasons (Experiment 3). Acclimation temperatures are denoted by horizontaldashed lines. $N$ is the number of replicates. Asterisks indicate significant departures of the selected temperatures from acclimation temperatures in particular treatments.

Different letters above the bars indicate treatments differing significantly from one another with respect to the selected temperature

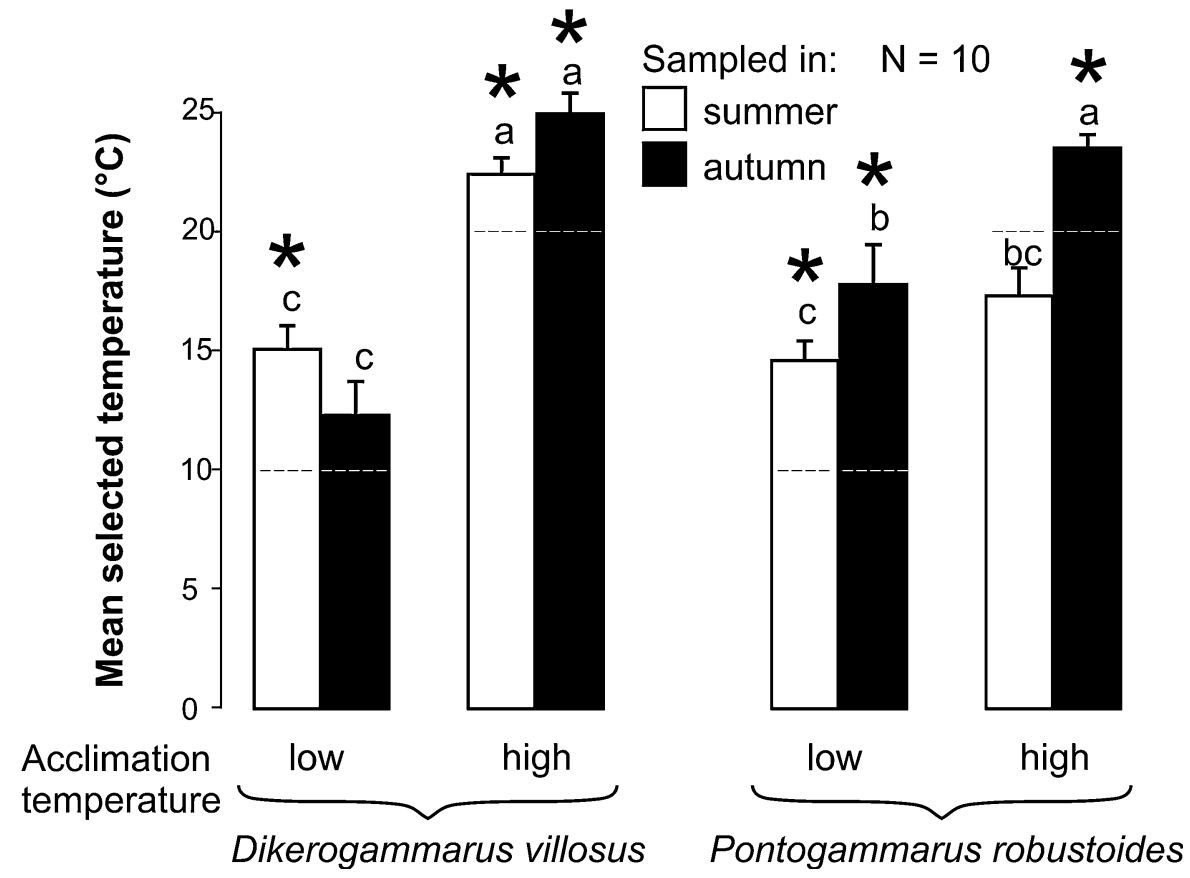

variable environment of Black Sea limans (Rozengurt, 1971). The studied species can inhabit waters of much higher salinity than those tested in our study, up to 6 PSU (Dobrzycka-Krahel \& Surowiec, 2011; Dobrzycka-Krahel et al., 2015), which roughly corresponds to $12000 \mu \mathrm{S} / \mathrm{cm}$ (Wagner et al., 2006). Pontogammarus robustoides has greater salinity resistance, surviving even in fully saline water of 34 PSU (Santagata et al., 2008) than D. villosus tolerating up to 20 PSU (Bruijs et al., 2001). This difference between the species may explain the affinity of $D$. villosus for lower conductivity in our experiment. Perhaps under conditions of highly fluctuating salinity, such a preference might help gammarids locate optimum microhabitats, e.g. by preventing their seaward migrations. Similarly, estuarine copepods exhibit counter-current migrations keeping them at a constant position within an estuary against the net seaward water movement (Shang et al., 2008). A direct response to conductivity gradients, observed in our study, might play such a role in the field.

Nevertheless, even despite their preferences, alien gammarids may have an advantage over their native counterparts due to the anthropogenically increased salinity of the large rivers they live in (Grabowski et al., 2009). However, an open question is why $D$. villosus avoids small affluents, which it should prefer with regard to their lower salinity. Maybe a fast water flow or variable (commonly lower) temperature in small streams (Allan \& Castillo, 2007) form such a barrier (see the discussion on these factors below), perhaps in association with low ionic content. Dikerogammarus villosus is less resistant to extreme values of other factors (e.g. temperature) in purely fresh water than in an oligohaline environment (Wijnhoven et al., 2003). On the other hand, it thrives in alpine lakes with low ionic content (BacelaSpychalska et al., 2013). Thus, in order to provide an unambiguous explanation of this phenomenon further studies are needed.

\section{Experiment 2: current velocity}

The gammarids showed no affinity for any of the tested flow velocities (Fig. 5A), which may limit their distribution to lentic areas or structured habitats (Jażdżewski et al., 2002; Żytkowicz et al., 2008; Grabowski et al., 2009; Borza et al., 2017). Avoidance of fast flowing waters distinguishes invasive amphipods from those staying within their native ranges (Devin \& Beisel, 2007). Native European gammarids have been observed to move actively upstream 
Fig. 7 Mean percentages ( \pm SE) of gammarids occupying particular compartments of the thermal gradient after acclimation to various temperatures in various seasons

(Experiment 3). Mean temperatures in particular compartments are shown in Fig. 3
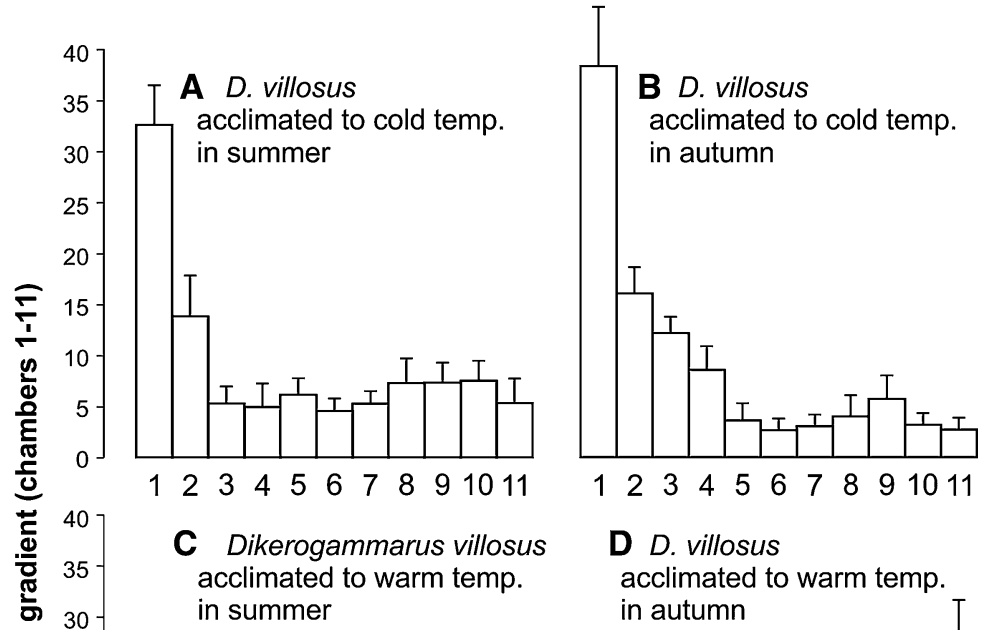
acclimated to warm temp. in autumn
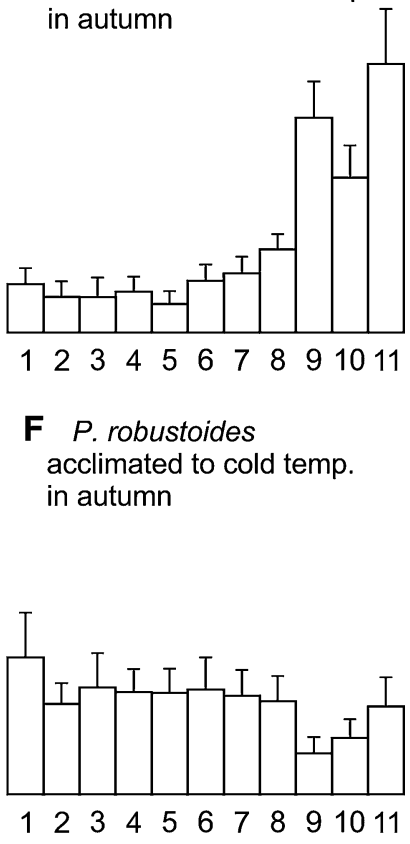

H P. robustoides acclimated to warm temp. in autumn 
(Dennert et al., 1969; Hultin, 1971) and prefer moderate flow velocities up to ca. $10 \mathrm{~cm} / \mathrm{s}$ (Hughes, 1970). This difference between native and alien gammarids corroborates their current distribution in Europe, where native species find refuges in smaller, fast flowing rivers and streams (Grabowski et al., 2009).

Nevertheless, the alien gammarids in our study withstood flow velocities up to $10 \mathrm{~cm} / \mathrm{s}$ with no significant changes in behaviour and were negatively affected by a current velocity of $\geq 15 \mathrm{~cm} / \mathrm{s}$. In the field, animals can use stones, woody debris or plants as flow refuges. Both studied species are associated with such objects (Kley et al., 2009; Jermacz et al., 2015) and showed the ability to utilize shelters (i.e. the downstream mesh) to stay within the flow zone at a flow of $15 \mathrm{~cm} / \mathrm{s}$. At a current velocity of $30 \mathrm{~cm} / \mathrm{s}$, gammarids changed their behaviour, moving to the stagnant water refuges (Fig. 5A). Thus, they were still able to counteract the flow and actively search for more suitable sites. The velocities used in our study cover the range typically observed in our sampling area (Gierszewski, 2006). Thus, we can assume that we comprised the entire range of gammarid responses to flow, from the neutral behaviour at low velocities to the avoidance of strong currents.

Dikerogammarus villosus seemed more affected by a high current water velocity than $P$. robustoides, as shown by its greater downward displacement (Fig. 5B) and higher change in activity (Fig. 5C). This difference between the species is surprising, considering that $D$. villosus is regarded as more associated with running waters (Bij de Vaate et al., 2002) than P. robustoides. Perhaps the adaptations of $P$. robustoides to commonly occupied sandy areas (Wawrzyniak-Wydrowska \& Gruszka, 2005; Żytkowicz et al., 2008), which are poorly sheltered and exposed to wave actions, allowed it to counteract the water flow in our experiment. In a field study, D. villosus was found to be the least rheotolerant compared to D. haemobaphes and D. bispinosus and the most associated with structured habitats offering protection against flow (Borza et al., 2017). Our experiment confirmed its ability to locate and utilize lentic microhabitats which can help it thrive in flowing waters.

The significantly longer duration of the upstream movement compared with the downstream relocation of D. villosus at the highest current velocity (Fig. 5C) may indicate a compensation for passive drifting. Given the greater downstream displacement of $D$. villosus under these conditions (Fig. 5B), such behaviour would reduce passive relocation and allow an animal to stay in the same position.

Many riverine organisms, including Gammarus spp., actively enter the water column to utilize the benefits of the flow (Dennert et al., 1969; Brittain \& Eikeland, 1988). They move upstream to compensate for passive drifting (Dennert et al., 1969; Hughes, 1970; Hultin, 1971), to approach an odour source (e.g. food) (Bousfield, 1978; Peckarsky \& Dodson, 1980; Pasternak et al., 2004) or to find a target of a long-distance migration (Arnold, 1974). They also drift downstream to avoid predators (Peckarsky \& Dodson 1980; Lancaster, 1990) or deteriorating conditions (Waters, 1972; Brittain \& Eikeland, 1988). Nevertheless, our study suggests that, although the tested Ponto-Caspian gammarids tolerate moderate flow velocities, they do not exhibit any positive rheotaxis.

\section{Experiment 3: temperature}

Both tested species generally preferred warm water, selecting higher temperatures than those to which they had been acclimated (Fig. 6). Particularly, D. villosus acclimated to a high temperature was often noted in the warmest part of the gradient (Fig. 7), at c.a. $35^{\circ} \mathrm{C}$ (Fig. 3). Such behaviour may seem maladaptive, as they would eventually die staying in such conditions for a longer time (personal observations). However, animals seldom encounter such extreme temperatures in the field and therefore the selection of the highest available temperature would allow them to find optimum thermal conditions.

Both native European and Ponto-Caspian gammarids tolerate a wide temperature range, up to ca. $30^{\circ} \mathrm{C}$ (Wijnhoven et al., 2003). Nevertheless, the gammarids did select particular temperatures in our study. Acclimation temperature strongly affected the choice of D. villosus, whereas the responses of $P$. robustoides depended more on the season (Fig. 6). Pontogammarus robustoides seemed to prefer warm water in the colder season and to avoid excessive heat in summer, suggesting a behavioural temperature regulation. Thus, this species appears to be better 
adapted to regulate its thermal conditions than $D$. villosus. Extreme shifts in temperature are usually found in shallow, unsheltered bottoms often inhabited by $P$. robustoides (Wawrzyniak-Wydrowska \& Gruszka, 2005; Żytkowicz et al., 2008), whereas $D$. villosus lives in deeper waters (Kley \& Maier, 2005; own observations in the sampling area) and/or on stony bottoms (Kley et al., 2009; Boets et al., 2010) where temperature regimes may be more constant. The effect of season (independent of acclimation) on thermal behaviour has also been observed in crabs (Cuculescu et al., 1998) and crayfish (Layne et al., 1985), but not in an isopod Asellus aquaticus, varying its thermal behaviour only in response to acclimation temperature (Lagerspetz \& Bowler, 1993), like D. villosus in our study.

Temperature selection was observed in many benthic and planktonic crustaceans (Lagerspetz \& Vainio, 2006). Usually, it is based on changes in activity and movement speed rather than on a directional taxis (Lagerspetz \& Vainio, 2006). Temperature in the aquatic environment may vary at a microscale, particularly in shallow near-shore areas, due to variable shading by the riparian canopy, floating plant leaves and submerged shelters as well as with the circadian cycle (Pokorny \& Kvet, 2003; Dallas \& Rivers-Moore, 2011). Thus, the ability to select appropriate temperature greatly increases the fitness of aquatic animals. Moreover, as predatory habits of $D$. villosus strongly depend on temperature, this factor also shapes its effects on aquatic communities (Van der Velde et al., 2009). Maazouzi et al. (2011) found that the ability of $D$. villosus to adapt physiologically to high temperature was lower than that of a native species. However, in the light of our results, the alien species seem to use another strategy and adjust their ambient temperature behaviourally.

Temperature also depends on the river size. In small streams, it is more variable and affected by external factors to a greater extent than in large rivers. Small tributaries with a dense riparian canopy are colder than wider rivers, less affected by their shoreline (Allan \& Castillo, 2007). Perhaps this may be one of the factors preventing alien gammarids, shown in our study to prefer warm waters, from entering smaller affluents, in which they have never been found so far (Grabowski et al., 2009).

\section{Conclusions}

In the field, multiple factors act simultaneously, interacting with each other and modifying their impacts on organisms. Therefore, it is difficult to account for interactive effects that occur in the field, and to extrapolate laboratory results directly to nature. However, our experimental study under controlled conditions is useful because it suggests cause-effect relationships between particular factors and animal responses.

We did not confirm gammarid affinity for increased ionic content. Thus, their avoidance of less saline small streams in favour of large rivers may partially depend on temperature or current velocity barriers, as suggested by our experiments. Consistent with our hypothesis, neither of the species exhibited preferences for flowing water, though they showed considerable capacity for dealing with moderate water velocities. However, contrary to our expectations, $D$. villosus was less resistant to the water flow than $P$. robustoides. Finally, in accordance with our hypothesis, $P$. robustoides selected more constant, seasonally dependent temperatures (cooler in summer, warmer in autumn), which may be beneficial in shallow areas often inhabited by this species.

The observed gammarid responses are likely to lead to their occurrence in warm, slowly flowing waters in the field. Given their distribution in the wild (Grabowski et al., 2009), low ionic content seems less important in their habitat selection, though, according to our study, a decrease in this parameter may also be beneficial for the studied species. Nevertheless, the ability to select an optimal microhabitat using thermal, hydrodynamic and salinity cues helps them survive under spatially and temporally variable conditions, which may contribute to their invasive potential. Relatively low selectivity with regard to water flow and, in the case of $P$. robustoides, salinity predestines them to live in a wide range of aquatic habitats.

Contrary to our expectations, we did not find strong differences in habitat preferences between the studied species. Even if they differed with regard to mechanisms of reactions, e.g. in the case of temperature, the final effect of their behaviour was similar (e.g. occupation of warmer areas). The similarity between the species, including their similar substratum preferences (Jermacz et al., 2015; Kobak et al., 2015), could 
potentially lead to strong interspecific competition and displacement. However, another study has demonstrated their variable depth preferences (with $P$. robustoides selecting shallower locations), which is likely to contribute to their separation and decrease competitive tensions in the field (Kobak et al., 2017).

Acknowledgements Our study was supported by a Grant of the National Science Centre Nos. 2012/05/B/NZ8/00479. We are grateful to Mrs Hazel Pearson for language corrections.

Open Access This article is distributed under the terms of the Creative Commons Attribution 4.0 International License (http:// creativecommons.org/licenses/by/4.0/), which permits unrestricted use, distribution, and reproduction in any medium, provided you give appropriate credit to the original author(s) and the source, provide a link to the Creative Commons license, and indicate if changes were made.

\section{References}

Allan, J. D. \& M. M. Castillo, 2007. Stream Ecology. Springer, Dordrecht.

Arnold, G. P., 1974. Rheotropism in fishes. Biological Reviews 49: 515-576.

Bącela-Spychalska, K., M. Grabowski, T. Rewicz, A. Konopacka \& R. Wattier, 2013. The "killer shrimp" Dikerogammarus villosus (Crustacea, Amphipoda) invading alpine lakes: overland transport by recreational boats and scuba-diving gear as potential entry vectors? Aquatic Conservation - Marine and Freshwater. Ecosystems 23: 606-618.

Bij de Vaate, A., K. Jażdżewski, H. A. M. Ketelaars \& G. van der Velde, 2002. Geographical patterns in range extension of Ponto-Caspian macroinvertebrate species in Europe. Canadian Journal of Fisheries and Aquatic Sciences 1174: 1159-1174.

Bock, D. G., C. Caseys, R. D. Cousens, M. A. Hahn, S. M. Heredia, S. Hübner, K. G. Turner, K. D. Whitney \& L. H. Rieseberg, 2015. What we still don't know about invasion genetics. Molecular Ecology 24: 2277-2297.

Boets, P., K. Lock, M. Messiaen \& P. L. M. Goethals, 2010. Combining data-driven methods and lab studies to analyse the ecology of Dikerogammarus villosus. Ecological Informatics 5: 133-139.

Borza, P., T. Huber, P. Leitner, N. Remund \& W. Graf, 2017. Current velocity shapes co-existence patterns among invasive Dikerogammarus species. Freshwater Biology 62: 317-328.

Bousfield, J. D., 1978. Rheotaxis and chemoreception in the freshwater snail Biomphalaria glabrata (Say): estimation of the molecular weights of active factors. Biological Bulletin 154: 361-373.

Brittain, J. E. \& T. J. Eikeland, 1988. Invertebrate drift - a review. Hydrobiologia 166: 77-93.

Bruijs, M. C. M., B. Kelleher, G. van der Velde \& A. Bij de Vaate, 2001. Oxygen consumption, temperature and salinity tolerance of the invasive amphipod Dikerogammarus villosus: Indicators of further dispersal via ballast water transport. Archiv für Hydrobiologie 152: 633-646.

Cuculescu, M., D. Hyde \& K. Bowler, 1998. Thermal tolerance of two species of marine crab, Cancer pagurus and Carcinus maenas. Journal of Thermal Biology 23: 107-110.

Dallas, H. F. \& N. A. Rivers-Moore, 2011. Micro-scale heterogeneity in water temperature. Water SA 37: 505-512.

Dennert, H. G., A. L. Dennert, P. Kant, S. Pinkster \& J. H. Stock, 1969. Upstream and downstream migrations in relation to the reproductive cycle and to environmental factors in the amphipod, Gammarus zaddachi. Bijdragen tot de Dierkunde 39: 1-43.

Devin, S. \& J. N. Beisel, 2007. Biological and ecological characteristics of invasive species: a gammarid study. Biological Invasions 9: 13-24.

Dick, J. T. A. \& D. Platvoet, 2000. Invading predatory crustacean Dikerogammarus villosus eliminates both native and exotic species. Proceedings of the Royal Society of London B: Biological Sciences 267: 977-983.

Dobrzycka-Krahel, A. \& J. Surowiec, 2011. Osmoregulation in Pontogammarus robustoides (G. O. Sars, 1894) (Amphipoda) and its distribution in the brackish waters of Northern Poland. Crustaceana 84: 1755-1767.

Dobrzycka-Krahel, A., M. Melzer \& W. Majkowski, 2015. Range extension of Dikerogammarus villosus (Sowinsky, 1894) in Poland (the Baltic Sea basin) and its ability to osmoregulate in different environmental salinities. Oceanological and Hydrobiological Studies 44: 294-304.

Gierszewski, P., 2006. Warunki przepływu wód przez Zbiornik Włocławski (Conditions of the water flow through the Włocławek Dam Reservoir). In: Olszewski A., \& K. Chutkowski (eds), Drogami wędrówek i badań Profesora Rajmunda Galona w 100. rocznicę urodzin (1906-2006). Przewodnik sesji terenowych, Oficyna Wydawnicza Turpress, Toruń, Poland: 250-254.

Grabowski, M., K. Bącela, A. Konopacka \& K. Jażdżewski, 2009. Salinity-related distribution of alien amphipods in rivers provides refugia for native species. Biological Invasions 11: 2107-2117.

Hawkins, A. J. S., 1996. Temperature adaptation and genetic polymorphism in aquatic animals. In Johnston, I. A. \& A. F. Bennett (eds), Animals and Temperature: phenotypic and Evolutionary Adaptation. Cambridge University Press Cambridge, New York: 103-126.

Hughes, D., 1970. Some factors affecting drift and upstream movements of Gammarus pulex. Ecology 51: 301-305.

Hultin, L., 1971. Upstream movements of Gammarus pulex (Amphipoda) in a South Swedish stream. Oikos 22: 329-347.

Jażdżewski, K., A. Konopacka \& M. Grabowski, 2002. Four Ponto-Caspian and one American gammarid species (Crustacea, Amphipoda) invading Polish waters. Contributions to Zoology 71: 115-122.

Jermacz, Ł., A. Dzierżyńska, M. Poznańska \& J. Kobak, 2015. Experimental evaluation of preferences of an invasive Ponto-Caspian gammarid Pontogammarus robustoides (Amphipoda, Gammaroidea) for mineral and plant substrata. Hydrobiologia 746: 209-221. 
Kley, A. \& G. Maier, 2005. An example of niche partitioning between Dikerogammarus villosus and other invasive and native gammarids: a field study. Journal of Limnology 64: $85-88$.

Kley, A., W. Kinzler, Y. Schank, G. Mayer, D. Waloszek \& G. Maier, 2009. Influence of substrate preference and complexity on co-existence of two non-native gammarideans (Crustacea: Amphipoda). Aquatic Ecology 43: 1047-1059.

Kobak, J., Ł. Jermacz \& A. Dzierżyńska-Białończyk, 2015. Substratum preferences of the invasive killer shrimp Dikerogammarus villosus. Journal of Zoology 297: 66-76.

Kobak, J., M. Rachalewski \& K. Bącela-Spychalska, 2016. Conquerors or exiles? Impact of interference competition among invasive Ponto-Caspian gammarideans on their dispersal rates. Biological Invasions 18: 1953-1965.

Kobak, J., Ł. Jermacz, D. Rutkowska, K. Pawłowska, L. Witkowska \& M. Poznańska, 2017. Impact of predators and competitors on the depth selection by two invasive gammarids. Journal of Zoology 301: 174-183.

Lagerspetz, K. Y. H. \& K. Bowler, 1993. Variation in heat tolerance in individual Asellus aquaticus during thermal acclimation. Journal of Thermal Biology 18: 137-143.

Lagerspetz, K. Y. H. \& L. A. Vainio, 2006. Thermal behaviour of crustaceans. Biological Reviews 81: 237.

Lampert, W. \& U. Sommer, 2007. Limnoecology: the Ecology of Lakes and Streams. Oxford University Press, New York.

Lancaster, J., 1990. Predation and drift of lotic macroinvertebrates during colonization. Oecologia 85: 48-56.

Layne, J., M. Manis \& D. Claussen, 1985. Seasonal variation in the time course of thermal acclimation in the crayfish $\mathrm{Or}$ conectes rusticus. Freshwater Invertebrate Biology 4: 98-104.

Llewelyn, J., B. L. Phillips, R. A. Alford, L. Schwarzkopf \& R. Shine, 2010. Locomotor performance in an invasive species: cane toads from the invasion front have greater endurance, but not speed, compared to conspecifics from a long-colonised area. Oecologia 162: 343-348.

Maazouzi, C., C. Piscart, F. Legier \& F. Hervant, 2011. Ecophysiological responses to temperature of the "killer shrimp" Dikerogammarus villosus: is the invader really stronger than the native Gammarus pulex? Comparative Biochememistry and Physiology - Part A: Molecular and Integrative. Physiology 159: 268-274.

MacNeil, C., J. T. A. Dick, D. Platvoet \& M. Briffa, 2011. Direct and indirect effects of species displacements: an invading freshwater amphipod can disrupt leaf-litter processing and shredder efficiency. Journal of the North American Benthological Society 30: 38-48.

McMahon, R. F., 1996. The physiological ecology of the zebra mussel, Dreissena polymorpha in North America and Europe. American Zoologist 36: 339-363.

Medley, K. A., 2010. Niche shifts during the global invasion of the Asian tiger mosquito, Aedes albopictus Skuse (Culicidae), revealed by reciprocal distribution models. Global Ecology and Biogeography 19: 122-133.

Müller, O. \& B. Baur, 2011. Survival of the invasive clam Corbicula fluminea (Müller) in response to winter water temperature. Malacologia 53: 367-371.

Pasternak, Z., B. Blasius, Y. Achituv \& A. Abelson, 2004. Host location in flow by larvae of the symbiotic barnacle Trevathana dentata using odour-gated rheotaxis. Proceedings of the Royal Society of London B: Biological Sciences 271: 1745-1750.

Pearman, P. B., A. Guisan, O. Broennimann \& C. F. Randin, 2008. Niche dynamics in space and time. Trends in Ecology and Evolution 23: 149-158.

Peckarsky, B. \& S. I. Dodson, 1980. Do stonefly predators influence benthic distributions in streams? Ecology 61: 1275-1282.

Piscart, C., J. C. Moreteau \& J. N. Beisel, 2005. Biodiversity and structure of macroinvertebrate communities along a small permanent salinity gradient (Meurthe River, France). Hydrobiologia 551: 227-236.

Pokorny, J. \& J. Kvet, 2003. Aquatic plants and lake ecosystems. In O'Sullivan, P. \& C. Reynolds (eds.), The Lakes Handbook. Limnology and Limnetic Ecology, Vol. 1. Blackwell Science Ltd, Malden: 309-340.

Ricciardi, A. \& H. J. MacIsaac, 2011. Impacts of biological invasions on freshwater ecosystems. In Richardson, D. M. (ed.), Fifty Years of Invasion Ecology: The Legacy of Charles Elton. Wiley-Blackwell, Hoboken: 211-224.

Rosa, I. C., J. L. Pereira, R. Costa, F. Gonçalves \& R. Prezant, 2012. Effects of upper-limit water temperatures on the dispersal of the Asian clam Corbicula fluminea. PLoS ONE 7: e46635.

Rozengurt, M. S., 1971. Issledovanie vliyaniya zaregulirovannogo stoka r. Dnestra na solevoi rezhim Dnestrovskogo limana (Analysis of the Impact of The Regulated River Runoff on Salt Regime of the Dniester Estuary). Naukova Dumka, Kiev, Ukraine.

Santagata, S., Z. R. Gasiunaite, E. Verling, J. R. Cordell, K. Eason, J. S. Cohen, K. Bącela, G. Quilez-Badia, T. H. Johengen, D. F. Reid \& G. M. Ruiz, 2008. Effect of osmotic shock as a management strategy to reduce transfers of nonindigenous species among low-salinity ports by ships. Aquatic Invasions 3: 61-76.

Shang, X., G. Wang \& S. Li, 2008. Resisting flow-laboratory study of rheotaxis of the estuarine copepod Pseudodiaptomus annandalei. Marine and Freshwater Behaviour and Physiology 41: 91-106.

Simberloff, D. \& L. Gibbons, 2004. Now you see them, now you don't! Population crashes of established introduced species. Biological Invasions 6: 161-172.

Torchin, M. E., K. D. Lafferty, A. P. Dobson, V. J. McKenzie \& A. M. Kuris, 2003. Introduced species and their missing parasites. Nature 421: 628-630.

van der Velde, G., R. S. E. W. Leuven, D. Platvoet, K. Bącela, M. A. J. Huijbregts, H. W. M. Hendriks \& D. Kruijt, 2009. Environmental and morphological factors influencing predatory behaviour by invasive non-indigenous gammaridean species. Biological Invasions 11: 2043-2054.

van Riel, M. C., G. van der Velde \& A. Bij de Vaate, 2011. Dispersal of invasive species by drifting. Current Zoology 57: 818-827.

Wagner, R. J., R. W. Boulger Jr., C. J. Oblinger, \& B. A. Smith, 2006. Guidelines and standard procedures for continuous water-quality monitors: station operation, record computation, and data reporting. U. S. Geological Survey Techniques and Methods 1-D3; accessed August 30, 2016 at https://pubs.usgs.gov/tm/2006/tm1D3/pdf/TM1D3.pdf.

Warren, D. L., M. Cardillo, D. F. Rosauer \& D. I. Bolnick, 2014. Mistaking geography for biology: inferring processes from 
species distributions. Trends in Ecology \& Evolution 29: 572-580.

Waters, T. F., 1972. The drift of stream insects. Annual Review of Entomology 17: 253-272.

Wawrzyniak-Wydrowska, B. \& P. Gruszka, 2005. Population dynamics of alien gammarid species in the River Odra estuary. Hydrobiologia 539: 13-25.

Wijnhoven, S., M. C. van Riel \& G. van der Velde, 2003. Exotic and indigenous freshwater gammarid species: physiological tolerance to water temperature in relation to ionic content of the water. Aquatic Ecology 37: 151-158.

Żytkowicz, J., J. Kobak, T. Kakareko \& A. Kentzer, 2008. Species composition and distribution of invasive PontoCaspian amphipods in the off-channel microhabitats of a temperate, lowland dam reservoir. International Review of Hydrobiology 93: 62-72. 